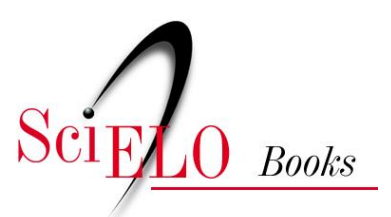

\title{
Ordem Stephanoberyciformes
}

\author{
Ana Cristina Teixeira Bonecker \\ Claudia Akemi Pereira Namiki \\ Márcia Salustiano de Castro \\ Paula Nepomuceno Campos
}

\section{SciELO Books / SciELO Livros / SciELO Libros}

BONECKER, ACT., et al. Ordem Stephanoberyciformes. In Catalogo dos estágios iniciais de desenvolvimento dos peixes da bacia de Campos [online]. Curitiba: Sociedade Brasileira de Zoologia, 2014, pp. 161-164. Zoologia: guias e manuais de identificação series. ISBN 978-85-98203-10-2.

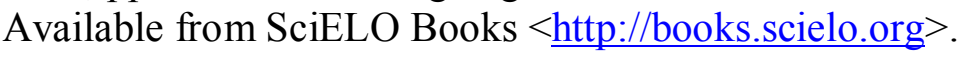

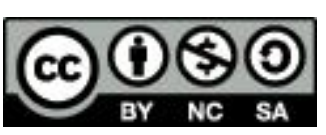

All the contents of this chapter, except where otherwise noted, is licensed under a Creative Commons Attribution-Non Commercial-ShareAlike 3.0 Unported.

Todo o conteúdo deste capítulo, exceto quando houver ressalva, é publicado sob a licença Creative Commons Atribuição Uso Não Comercial - Partilha nos Mesmos Termos 3.0 Não adaptada.

Todo el contenido de este capítulo, excepto donde se indique lo contrario, está bajo licencia de la licencia Creative Commons Reconocimento-NoComercial-CompartirIgual 3.0 Unported. 


\section{Ordem Stephanoberyciformes}

A ordem Stephanoberyciformes é representada por nove famílias e 75 espécies exclusivamente marinhas. São peixes pequenos que vivem em regiões profundas. Algumas larvas são muito semelhantes aos adultos (Melamphaidae), enquanto outras se tornam muito diferentes.

Nesse estudo a ordem Stephanoberyciformes é representada pela família Melamphaidae. 


\section{Família Melamphaidae}

A família Melamphaidae é a maior e mais diversa da ordem Stephanoberyciformes, incluindo cinco gêneros com 36 espécies. São encontradas em regiões meso e batipelágicas, em zonas oceânicas de todo mundo. Podem possuir três padrões de pigmentação e diferentes tipos de ornamentação na cabeça (incluindo espinhos e cristas), que distinguem os gêneros.

No Brasil já foram identificadas sete espécies nas fases de larva e adulto. Nesse estudo são contempladas as espécies Poromitra capito e Melamphaes simus, ambas novas ocorrências para o Brasil. 


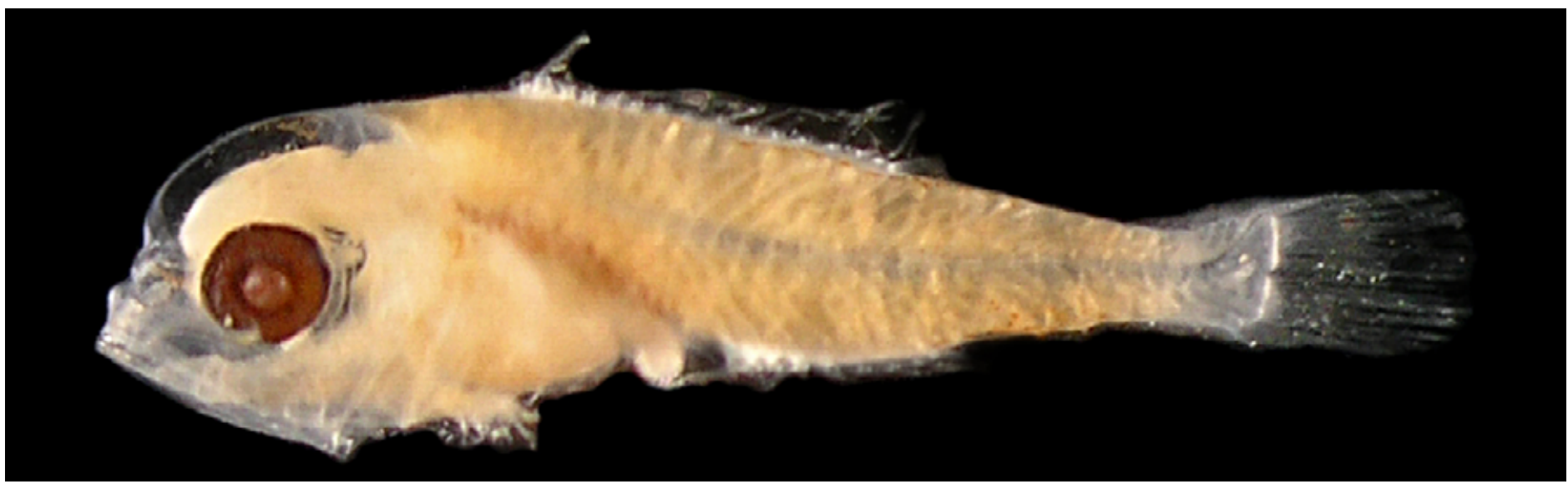

Figura 94 - A: Melamphaes simus. A. DZUFRJ 5501; Flexão; CP 5,4 mm.

\section{Melamphaes simus Ebeling, 1962}

Possui o corpo alongado (28-30 miômeros) durante todo desenvolvimento. A distância pré-anal aumenta de $29-35 \%$ CP durante a pré-flexão para 61-64\% CP em juvenis. Não possui espinhos na cabeça. A nadadeira pélvica começa abaixo ou um pouco depois da base da nadadeira peitoral. O padrão de pigmentação e o número de rastros presentes no primeiro arco branquial são as principais características que separam as espécies. No estágio de pré-flexão possui manchas de pigmentos dorsais e ventrais, presença de pigmentos peritoneais e internos sobre a cabeça. A partir da flexão há uma linha de melanóforos na margem dorsal do corpo e no pedúnculo caudal. Apresentam três espinhos e 15-16 raios na nadadeira dorsal e um espinho e oito a dez raios da nadadeira anal. Número de rastros: 4+11-12.

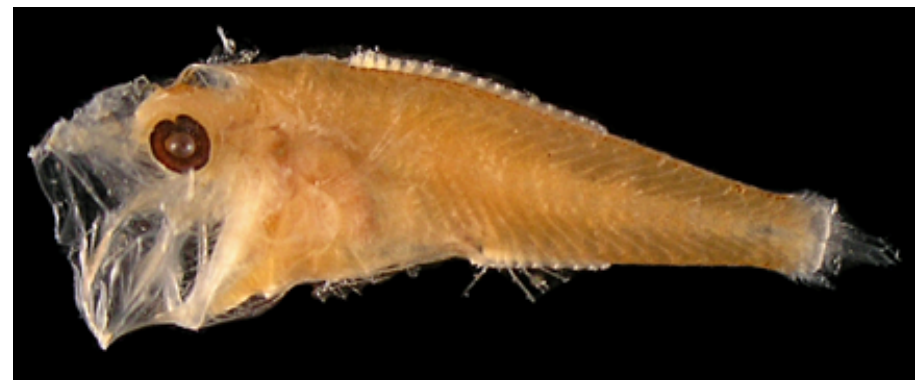

Figura 94 - B: DZUFRJ 119; Pós-flexão; CP 7,3 mm.

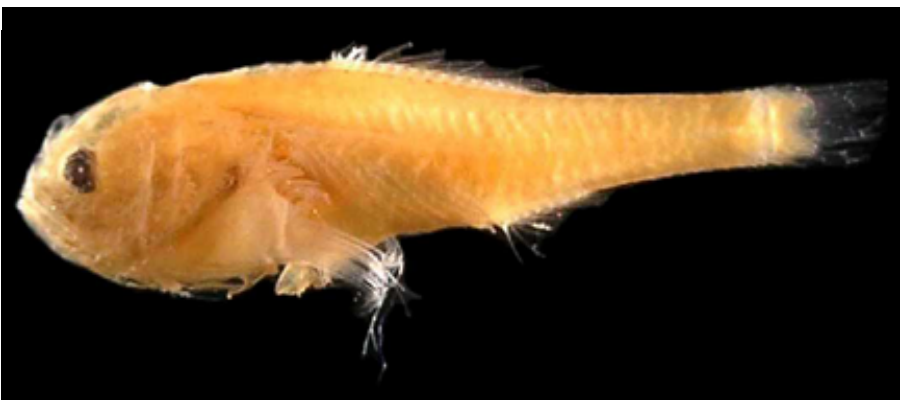

Figura 94 - C: DZUFRJ 5499; Transformação; CP 11,0 mm.

Tamanho: flexão 3,1-5,6 mm; pós-flexão 7,3 mm; transformação 11,0 mm.

Habitat: espécie marinha, mesopelágica e batipelágica, ocorre em regiões oceânicas entre 400 e $1.000 \mathrm{~m}$ de profundidade durante o dia. A noite ocorre desde a superfície até $600 \mathrm{~m}$ de profundidade.

\section{Georreferrenciamento}

\begin{tabular}{|c|c|c|c|c|c|c|c|c|}
\hline DZUFR & Latitude (S) & Longitude (W) & Data & $\begin{array}{c}\text { Tipo de } \\
\text { arrasto }\end{array}$ & $\begin{array}{c}\text { Profundidade } \\
\text { de coleta }\end{array}$ & Rede & $\begin{array}{c}\text { Malha } \\
\text { ( } \boldsymbol{\mu m})\end{array}$ & $\begin{array}{c}\mathbf{N}^{\circ} \text {. de } \\
\text { inds. }\end{array}$ \\
\hline 5499 & $22^{\circ} 32^{\prime} 49,0^{\prime \prime}$ & $040^{\circ} 04^{\prime} 20,9^{\prime \prime}$ & $07 / 11 / 2001$ & oblíquo & $1.000 \mathrm{~m}$ & cilíndrico-cônica & 500 & 4 \\
\hline 5500 & $22^{\circ} 31^{\prime} 40,9^{\prime \prime}$ & $040^{\circ} 02^{\prime} 39,6^{\prime \prime}$ & $07 / 11 / 2001$ & oblíquo & $1.000 \mathrm{~m}$ & cilíndrico-cônica & 500 & 1 \\
\hline 5501 & $22^{\circ} 32^{\prime} 50,0^{\prime \prime}$ & $040^{\circ} 04^{\prime} 09^{\prime \prime}$ & $06 / 11 / 2001$ & oblíquo & $1.000 \mathrm{~m}$ & cilíndrico-cônica & 500 & 4 \\
\hline 5502 & $22^{\circ} 32^{\prime} 50,0^{\prime \prime}$ & $040^{\circ} 04^{\prime} 09^{\prime \prime}$ & $06 / 11 / 2001$ & oblíquo & $1.000 \mathrm{~m}$ & cilíndrico-cônica & 500 & 8 \\
\hline
\end{tabular}

Referências: Sandknop \& Watson, 1996a; Garcia \& Morgan, 2002; Kotlyar, 2004; Frias-Torres, 2006a; Fahay, 2007; Campos et al., 2008; Froese \& Pauly, 2014. 


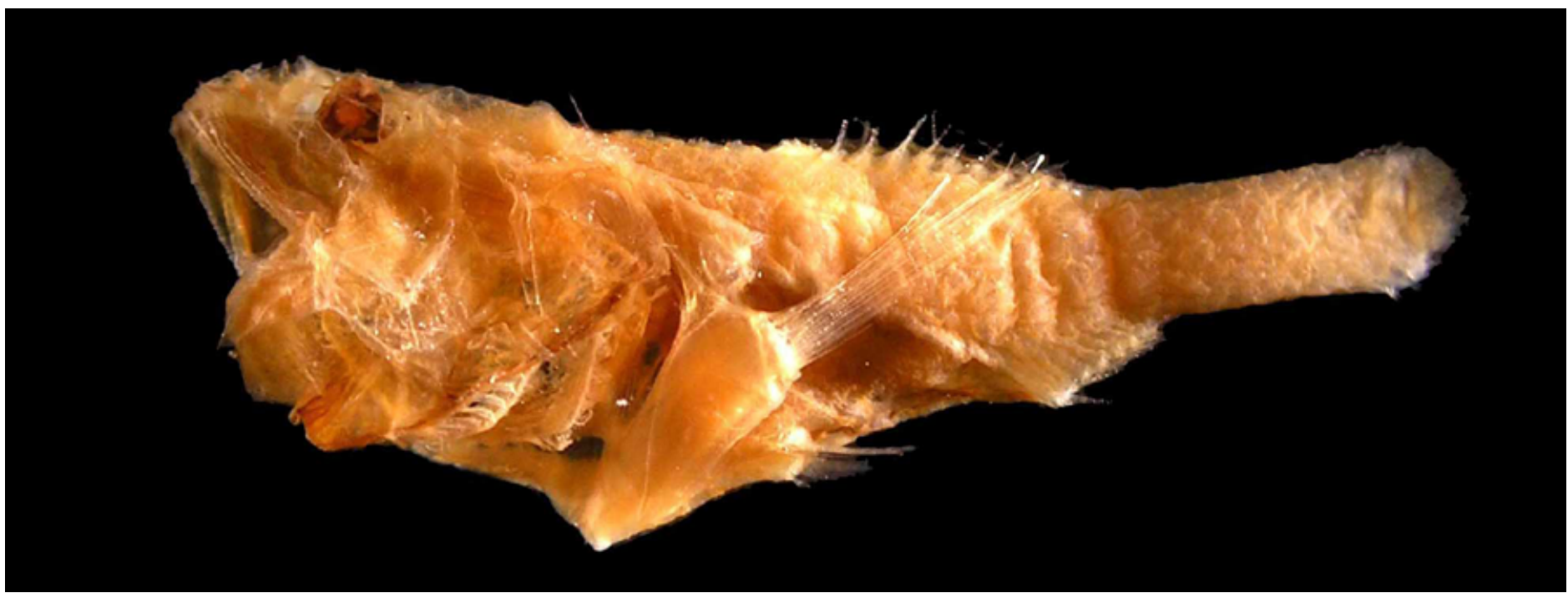

Figura 95: Poromitra capito. A. DZUFRJ 7512;Transformação; CP 20,8 mm.

\section{Poromitra capito Goode \& Bean, 1883}

O corpo é comprimido lateralmente, a cabeça é grande e os olhos são pequenos. O pedúnculo caudal é moderadamente alongado e o número de miômeros varia entre 25-26. A distância pré-anal é de aproximadamente $60 \%$ CP durante todo desenvolvimento. As larvas dessa espécie possuem várias cristas na região cefálica e muitos espinhos no pré-opérculo (3-4) e opérculo. A nadadeira dorsal é formada por três espinhos e 11 raios, enquanto a anal possui um espinho e oito raios. O número de rastros no primeiro arco branquial é fundamental para separação das espécies $(10+22)$. O número total de miômeros varia entre 25 e 26.

Tamanho: transformação 20,8 mm.

Habitat: espécie marinha, mesopelágica e batipelágica, ocorre em regiões oceânicas entre 750 e $1.550 \mathrm{~m}$ de profundidade durante o dia. A noite ocorre entre 100 e 750 m de profundidade.

\section{Georreferrenciamento}

\begin{tabular}{|c|c|c|c|c|c|c|c|c|}
\hline DZUFRJ & Latitude (S) & Longitude (W) & Data & $\begin{array}{c}\text { Tipo de } \\
\text { arrasto }\end{array}$ & $\begin{array}{c}\text { Profundidade } \\
\text { de coleta }\end{array}$ & Rede & $\begin{array}{c}\text { Malha } \\
\text { ( } \boldsymbol{\mu m})\end{array}$ & $\begin{array}{c}\mathbf{N}^{\circ} \text {. de } \\
\text { inds. }\end{array}$ \\
\hline 7512 & $21^{\circ} 54^{\prime} 36,5^{\prime \prime}$ & $039^{\circ} 4^{\prime} 20,0^{\prime \prime}$ & $10 / 10 / 2001$ & oblíquo & $1.000 \mathrm{~m}$ & cilíndrico-cônica & 500 & 1 \\
\hline
\end{tabular}

Referências: Sandknop \& Watson, 1996a; Garcia \& Morgan, 2002; Kotlyar, 2004; Frias-Torres, 2006a; Fahay, 2007; Campos et al., 2008; Froese \& Pauly, 2014. 